\title{
An important update on medical consent
}

\author{
David SY Wong *, MB, BS, LLB (London) \\ Department of Surgery, The Chinese University of Hong Kong, Prince of Wales Hospital, Shatin, Hong Kong \\ * Corresponding author: sywong@surgery.cuhk.edu.hk \\ Hong Kong Med J 2015;21:376-7 \\ DOI: 10.12809/hkmj154594
}

The central tenet of consent in medical practice is that the patient understands the options and their risks and benefits. This in turn facilitates free choice by the patient of what will be done and is in accordance with the fundamental human right to exercise autonomy over one's own body. In addition to good medical practice, proper consent is a legal requirement and can be the most important pitfall in allegations of assault or clinical negligence.

As a result of the landmark decision of the Supreme Court of the United Kingdom of 11 March 2015, Montgomery v Lanarkshire Health Board,${ }^{1}$ the law of consent has radically been updated. This is going to have far-reaching implications for medical practice in all common law jurisdictions.

As is usual with litigation for clinical negligence, the events involved an unfortunate story. A 5-feet-1-inch tall insulin-dependent diabetic with an understandably large-size fetus had asked her obstetrician whether there were any anticipated difficulties in vaginal delivery. It was the testimony of the obstetrician in court that she was concerned that the patient would have elected to have a caesarean section, had she been warned of the approximate $10 \%$ risk of shoulder dystocia. The obstetrician thus acted in what she perceived to be the patient's best interests and did not advise her of the risk. Sadly during delivery, the baby suffered brachial plexus injury and anoxia which resulted in permanent neurological damage.

There should be no undue influence or withholding of information when obtaining medical consent. But how often it is heard 'It is a matter of how you explain to the patient!? Well-intentioned, caring, and empathic doctors not uncommonly have a tendency to present their explanations skilfully in such a way that the patient is guided to make a decision that is believed by the doctor to be in the patient's best interests. Is this genuinely providing the patient with free choice? Is the doctor imposing his opinion and thus decision on the patient?

The English law governing consent has hitherto been exemplified by the previous landmark judgement in Sidaway $v$ Board of Governors of the Bethlem Royal Hospital ${ }^{2}$ in 1985. In this important decision, the Law Lords instrumentally extended the Bolam standard, ${ }^{3}$ applicable to alleged mistakes in diagnosis and treatment, to the arena of medical consent. They explicitly reserved the final decision of what needed to be disclosed to patients for the purpose of obtaining consent to be 'primarily a matter of clinical judgement'. Only when specifically asked by a patient for details on a particular aspect was the doctor required to provide full information about it. The transatlantic 'fully informed consent' approach was not accepted and doctors were to inform patients what, in their opinion, patients should know and what most other doctors would disclose in similar circumstances.

This is now history. What Montgomery handed down is that by selectively filtering some information from the knowledge of the patient and subtly leading the patient towards making a certain choice, the patient is actually deprived of the right of autonomy in making his/her own choice. That is not genuine consent of the patient and it is not what obtaining consent is about. There is also no room for waiting for the occasional inquisitive patient to voice a concern before details are provided. The doctor should volunteer information to which a reasonable patient would attach significance, taking into account the circumstances of the patient.

Does this mean that we are now adopting the 'fully informed' consent approach? I suspect that the answer is no. It is not a broad-brush requirement of everything related to the intervention, but that to which the prudent patient would attach significance and that the doctor knows or should reasonably know is relevant. And so this is now the test for whether a doctor has fulfilled his/her duty of care on risk disclosure in the obtaining of consent. The Bolam standard of whether the withholding of certain information, for example where a risk is lower than a certain arbitrary percentage, is in accordance with a reasonable body of medical opinion', becomes immaterial. This is really a patient-centred approach and is the modern approach already adopted in American and Australian judgements widely known as the 'prudent patient test'. The paternalistic view of 'doctors know best' or 'putting oneself in the good hands of the doctor' belongs to the past. Adult patients with adequate mental capacity can and should decide for themselves and have their right to do so protected by the law. Colleagues are well aware that this right of choice is not limited to decisions that others might regard as sensible. It exists notwithstanding that the reasons for making the choice are rational, irrational, unknown, or even 
non-existent (per Lord Donaldson, $\left.\operatorname{Re} T(A d u l t)^{4}\right)$.

To put it another way, the previously favoured 'prudent doctor approach' would have the doctor decide, using his/her clinical judgement, what the patient should know, including frequent or serious risks. The now adopted 'prudent patient test' requires the doctor to disclose what he can reasonably see as information that is significant in the patient's evaluation in decision-making. The doctor is no longer the person to decide what should be disclosed, it is dictated by the patient's needs from the latter's perspective. A good illustration of the last point is the case of Rogers $v$ Whitaker ${ }^{5}$ where the doctor had failed to disclose the rare 1 in 14000 risk of sympathetic ophthalmia to a patient undergoing surgery on her blind eye to improve appearance. The patient became totally blind due to this rare complication.

The judgement also reminded practitioners not to abuse the 'therapeutic exception' to withhold information where the release of certain information might be detrimental to the wellbeing of the patient.

Patients are no longer passive recipients of medical care. They participate in and are responsible for their own decisions. The new legal requirements have brought standards of consent in line with today's socio-cultural scenario.

The Supreme Court of the United Kingdom is the highest tier of the court system and one of the last resorts for any appeals from the lower courts. It assumed the judicial functions of the Appellate Committee of the House of Lords in 2009 as the new court of final appeal in the United Kingdom.

In conclusion, between professional opinion of what is best and the true exercise of a patient's right to choose, the latter prevails. The doctor is obliged to take reasonable care to ensure a patient understands the material risks in proposed interventions including those of viable alternatives. A 'material risk' is one to which a reasonable patient in his/her circumstances would attach significance. Good and effective communication remains vital.

\section{References}

1. Montgomery v Lanarkshire Health Board, UKSC 11 (2015).

2. Sidaway $\mathrm{v}$ Board of Governors of the Bethlem Royal Hospital, AC 871 (1985).

3. Bolam v Friern Hospital Management Committee, 1 WLR 582 (1957).

4. Re T (Adult), 4 All ER 649 (1992).

5. Rogers v Whitaker, 175 CLR 479 (1992). 